\title{
Tumor Necrosis Factor Mediates Experimental Pulmonary Edema by ICAM-1 and CD18-dependent Mechanisms
}

\author{
Siu K. Lo," John Everitt, ${ }^{\star}$ Jiang Gu, and Asrar B. Malik* \\ ${ }^{\ddagger}$ Department of Physiology and Cell Biology, The Albany Medical College of Union University, Albany, New York 12208; \\ *Vascular Research Division, Department of Pathology, Brigham and Women's Hospital, Harvard Medical School, \\ Boston, Massachusetts 02115; and \$ Deborah Research Institute, Browns Mills, New Jersey 08015-1799
}

\begin{abstract}
(TNF ${ }_{\alpha}$-induced sequestration of neutrophils (PMN) in lungs and of the resultant PMN-dependent pulmonary edema. Guinea pig lungs perfused with Ringers-albumin were challenged with $\mathrm{TNF}_{\alpha}(1,000 \mathrm{U} / \mathrm{ml})$ for $90 \mathrm{~min}$, followed by addition of fresh perfusate containing $2 \times 10^{7}$ human PMN. TNF challenge caused sequestration of PMN in the pulmonary vascular bed as indicated by a threefold increase in lung tissue myeloperoxidase activity (MPO). The activation of the sequestered PMN with phorbol 12-myristate 13-acetate (PMA; 5 $\left.\times 10^{-9} \mathrm{M}\right)$ produced threefold increases in pulmonary artery $\left(\mathbf{P}_{\overline{\mathbf{p a}_{0}}}\right)$ and pulmonary capillary hydrostatic $\left(\mathbf{P}_{\overline{\mathrm{cap}}}\right)$ pressures, and twofold increases in lung wet-to-dry weight $(W / D)$ ratio and capillary filtration coefficient $\left(K_{t, c}\right)$ over baseline. $T N_{\alpha}$ prestimulation was required for these responses since activation of PMN with PMA in control lungs produced smaller increases in $P_{\overline{p a n}}$ and $P_{\overline{c a p}}(P<0.01)$ and did not change the $W / D$ and $K_{\mathrm{f}, c^{\circ}}$ TNF $_{\alpha}$ prestimulation also induced the expression of intercellular adhesion molecule (ICAM-1) on pulmonary vascular endothelial cells. Monoclonal antibodies (mAbs) to the neutrophil CD18 integrin ( $\beta$-chain of CD11/CD18 complex) (mAb IB4) and to its endothelial cell ligand ICAM-1 (mAb RR1/1) were used to examine the role of PMN adhesion in the TNF $_{\alpha}$ induced responses. Pretreatment of PMN with $\mathrm{mAb}$ IB4 prevented PMN uptake and increases in $P_{\overline{p a n}}, P_{c \bar{c},}, K_{t, c}$ and $W / D$ ratio. Addition of $\mathrm{mAb} R R 1 / 1$ to the perfusate reduced $P M N$ uptake by $58 \%$, and prevented the increases in $P_{\bar{m}}, P_{c a p}, K_{f, e}$ and $W / D$ ratio, as with $m A b$ IB4. The findings indicate that TNF $_{\alpha}$ prestimulation of lungs mediates PMN uptake and that this requires the expression of ICAM-1 and its interaction with CD18 integrin on PMN. The activation of PMN sequestered by ICAM-1-dependent mechanism contributes to the development of pulmonary vascular injury and edema. (J. Clin. Invest. 1992. 89:981-988.) Key words: vascular permeability • endothelial adhesion molecules $\bullet$ neutrophil activation • pulmonary capillary pressure $\bullet$ CD18 integrin
\end{abstract}

Address correspondence and reprint requests to Dr. A. B. Malik, Department of Physiology and Cell Biology, A66, 47 New Scotland Avenue, Albany, NY 12208.

Received for publication 16 August 1990 and in revised form 12 November 1991.

J. Clin. Invest.

(c) The American Society for Clinical Investigation, Inc.

0021-9738/92/03/0981/08 $\$ 2.00$

Volume 89, March 1992, 981-988

\section{Introduction}

The release of tumor necrosis factor-alpha $\left(\mathrm{TNF}_{\alpha}\right)^{1}$ during septicemia (1) has been linked to neutrophil (PMN)-mediated vascular injury in the septic shock syndrome (2). The bacterial product, lipopolysaccharide (LPS), causes the release of $\mathrm{TNF}_{\alpha}$ from monocytes (3), which may in turn induce endothelial hyperadhesivity towards leukocytes $(4,5,6)$ by expression of cell surface adhesion molecules such as the intercellular adhesion molecule (ICAM-1) and endothelial adhesion molecule (ELAM-1) (6, 7). Expression of these endothelial adhesion molecules is a critical factor in the binding of leukocytes to the vessel wall at sites of inflammation $(8,9)$. Neutrophils (PMN) activation can injure the endothelial cells and cause tissue edema $(8,9,10,11)$. Adhesion of PMN to the endothelial cell monolayer appears to be the essential requirement for the mediation of endothelial injury, because the adherent cells are capable of producing greater amounts of oxidants than nonadherent PMN (12).

In the present study, we examined whether expression of endothelial cell adhesivity is a determinant of PMN uptake in the pulmonary microcirculation, and whether activation of endothelial cells by this mechanism contributes to PMN-mediated lung vascular injury and edema. The results indicate that $\mathrm{TNF}_{\alpha}$ prestimulation of lungs causes sequestration of PMN in lungs such that subsequent PMN activation increases lung vascular permeability and tissue water content. The PMN uptake in pulmonary microvessels is the result, in part, of the interaction of the expressed ICAM-1 ligand with the PMN CD18 integrin.

\section{Methods}

Materials. mAbs IB4 (anti-CD18) and OKM-1 (anti-CD1 1b) were supplied by Dr. S. D. Wright (The Rockefeller University, New York), and the anti-ICAM-1 mAb (RR1/1) was supplied by Dr. R. Rothlein (Boehringer-Ingelheim, Ridgefield, CT). MAb OKM-1, directed against an irrelevant epitope on CD11b, was used as a control mAb since it does not prevent neutrophil adhesion to endothelial cells (13). Recombinant human $\mathrm{TNF}_{\alpha}$ (specific bioactivity of $25 \times 10^{6} \mathrm{U}$ of TNF/ $\mathrm{mg}$ of protein) was obtained from Cetus Corp. (Emeryville, CA). A TNF unit was defined as the amount producing 50\% cytotoxicity of L929 cells seeded at $2 \times 10^{5}$ cells per ml after an 18-h incubation at

1. Abbreviations used in this paper: $\mathrm{ABC}$, avidin-biotin-peroxidase complex; ICAM-1, intercellular adhesion molecules; MPO, myeloperoxidase; PMA, phorbol 12-myristate 13-acetate; $\mathrm{TNF}_{\alpha}$, tumor necrosis factor-alpha. 
$37^{\circ} \mathrm{C}(10)$. Endotoxin contamination was $<20 \mathrm{pg} / \mathrm{ml}$ by Limulus amebocyte lysate assay. Phorbol 12-myristate 13-acetate (PMA) and cycloheximide were purchased from Sigma Chemical Co. (St. Louis, MO).

Lung perfusion preparation. The isolated-perfused guinea pig lung preparation was used as described (14). This preparation allows simultaneous measurements of pulmonary artery $\left(\mathrm{P}_{\overline{\mathrm{pa}}}\right)$ and capillary hydrostatic pressures $\left(\mathrm{P}_{\overline{c a p}}\right)$, lung wet weight, and transvascular water permeability (capillary filtration coefficient, $\boldsymbol{K}_{\mathrm{f}, \mathrm{c}}$ ), under controlled flow conditions. Hartley guinea pigs were anesthetized with pentobarbital sodium ( $50 \mathrm{mg} / \mathrm{kg}$ i.p.; Abbott Laboratories, North Chicago, IL). The trachea was cannulated before opening the thorax, and sodium heparin $(700 \mathrm{U} / \mathrm{kg})$ was administrated via intracardiac injection to prevent blood clotting. The heart and lung were removed en bloc and suspended from a counterweighted beam balance. Catheters were placed in pulmonary artery and left atrium. Left atrial pressure and airway pressure transducers were adjusted to 3 and $1 \mathrm{~cm} \mathrm{H}_{2} \mathrm{O}$, respectively, and held constant at these values during the experiment. Perfusion of the lung was begun with a peristaltic pump (model 1215; Harvard Apparatus Co., Inc., Millis, MA) within minutes of removal of the lung. The perfusate consisted of a phosphate-buffered Ringer's-albu$\min (0.5 \mathrm{~g} / 100 \mathrm{ml})$ solution (no difference was noted with higher perfusate albumin concentrations). The perfusion rate was set at $28 \mathrm{ml} / \mathrm{min}$ for all experiments, with a reservoir volume of $300 \mathrm{ml}$. $\mathrm{P}_{\overline{\mathrm{cap}}}$ was determined using the double-occlusion method as described (14). The $K_{\mathrm{f}, \mathrm{c}}$ was also determined during isogravimetric periods as described (14) (the $K_{\mathrm{f}, \mathrm{c}}$ values were expressed in units of $\mathrm{ml} / \mathrm{min}$ per $\mathrm{cm} \mathrm{H}_{2} \mathrm{O}$ per $\mathrm{g}$ dry $w t)$. In separate experiments, the time-dependent changes in lung wet weight were used to quantify the time course of lung water accumulation (14). At the end of experiments, lungs were drained and dissected free of nonpulmonary tissue, and the tissue was dried to a constant weight at $50^{\circ} \mathrm{C}$ for $2 \mathrm{~d}$. Pulmonary edema was determined by the lung wet/dry weight ratio.

$P M N$ isolation. Human PMN were isolated using Ficoll-Hypaque method (15). Purity of PMN was $>99 \%$ by Wright's stain, and viability of PMN was $>98 \%$ as determined by trypan blue exclusion.

Experimental protocols. The general experimental protocol is indicated in Fig. 1. The lungs were treated with $\mathrm{TNF}_{\alpha}$ for $90 \mathrm{~min}$ by injecting $\operatorname{TNF}_{\alpha}(1,000 \mathrm{U} / \mathrm{ml})$ into the perfusate after the initial baseline measurements. $\mathrm{TNF}_{\alpha}$ challenge alone did not produce significant changes in the lung weight and hemodynamic parameters monitored during the experimental period $(n=5)$. Fresh perfusate was added to replace circulating $\mathrm{TNF}_{\alpha}$ at the end of the 90 -min period. Freshly isolated PMN $\left(2 \times 10^{7}\right.$ cells $)$ were then infused into the pulmonary artery catheter within $5 \mathrm{~min}$; phorbol 12-myristate 13-acetate (PMA; $5 \times 10^{-9} \mathrm{M}$ ) was administered within 2-5 min after the PMN infusion $(n=6)$ (group I). In other groups, lungs were perfused with $\mathrm{TNF}_{\alpha}$ for $5 \mathrm{~min}$, and then PMN were added to the perfusate $85 \mathrm{~min}$ later, followed by the PMA challenge $(n=4)$ (group II), or lungs were challenged with $\mathrm{TNF}_{\alpha}$ for 5 min before the addition of the PMN and the PMA challenge $(n=5)$ (group III). The times of these interventions followed the general protocol outlined in Fig. 1.

Control experiments for group I examined the effects of 90-min $\mathrm{TNF}_{\alpha}$ challenge alone $(n=5), \mathrm{PMA}$ alone $(n=5), \mathrm{PMN}$ alone $(n=5)$,

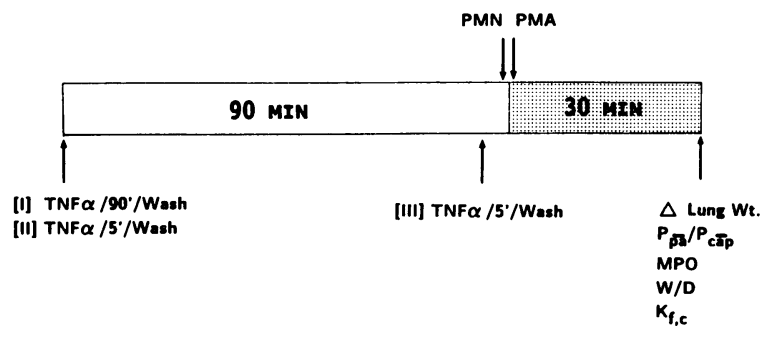

Figure 1. The general protocol of the outlined experiments.
$\mathrm{TNF}_{\alpha}(90 \mathrm{~min})$ plus PMA $(n=5), \mathrm{TNF}_{\alpha}(90 \mathrm{~min})$ plus $\operatorname{PMN}(n=5)$, and PMA plus $\mathrm{PMN}(n=5)$.

The role of CD18 integrin ( $\beta$-chain of CD11/CD18 glycoprotein) of PMN was studied by incubating isolated PMN $\left(2 \times 10^{7}\right.$ cells $)$ with either $\mathrm{mAb}$ IB4 $(0.7 \mathrm{mg} / \mathrm{ml})(n=5)$ or with control mAb OKM-1 $(0.7$ $\mathrm{mg} / \mathrm{ml}[n=5])$ for $20 \mathrm{~min}$ on ice, before injection of the treated PMN into the pulmonary circulation as above. The role of ICAM-1 was studied, using anti-ICAM-1 mAb RR1/1 $(0.7 \mathrm{mg} / \mathrm{ml})$ injected into the perfusate just before infusion of $\operatorname{PMN}(n=5)$. In another experiment $(n=$ 4), the effects of cycloheximide $(10 \mu \mathrm{g} / \mathrm{ml})$ added to the perfusate 10 min before 90 -min $\mathrm{TNF}_{\alpha}$ challenge period was studied to assess whether the response required protein synthesis.

ICAM-1 immunostaining. mAb RR1/1 reactivity with guinea pig lung tissue was tested after fixing lung sections with freshly prepared $4 \%$ paraformaldehyde in PBS $(0.01 \mathrm{M}, \mathrm{pH} 7.3)$ for $3 \mathrm{~h}$, followed by wash in PBS containing 14\% sucrose overnight. The samples were then dehydrated through graded alcohols and xylene, and embedded in paraffin. Consecutive sections ( $7-\mu$ thick) were cut and mounted on poly-L-lysine coated glass slides (16). After dewaxing, two sections from each region were stained with hematoxylin and eosin to assess the general morphology. Four slides from each region were immunostained with mAb RR1/1 (diluted 1:40 in PBS). The avidin-biotin-peroxidase complex $(\mathrm{ABC})$ method (17) was used with an $\mathrm{ABC}$ immunostaining kit from Vector Laboratories, Inc. (Burlingame, CA). The primary antibody was incubated for $24 \mathrm{~h}$ at room temperature. After washing in PBS (three times) for $5 \mathrm{~min}$, the sections were reacted with biotin-labeled rabbit antimouse antiserum (diluted 1:100 in PBS) for $40 \mathrm{~min}$ at room temperature. The sections were then incubated with freshly prepared $\mathrm{ABC}$ solution for $\mathbf{4 0} \mathrm{min}$ at room temperature. The labeling peroxidase was colorized with chromogen diaminobenzidine (DAB) and hydrogen peroxide. The slides were counterstained with hematoxylin and coverslipped. Controls for the immunostaining included normal mouse serum (instead of the mAb RR1/1), and a preabsorption test. For the latter, the human cell line (U-937, monocyte-like histocytic lymphoma obtained from ATCC, CRL 1593), known to contain the ICAM-1 antigen on the cell membrane, was preincubated with $\mathrm{mAb}$ $\mathrm{RR} 1 / 1$ at $4^{\circ} \mathrm{C}$ overnight (diluted 1:40). The supernatant was used as the first layer of immunostaining. The preincubation was intended to deplete the antibody, thereby establishing whether the positivity detected with the mAb was due to RR1/1 binding to the expressed antigen in lung tissue.

Myeloperoxidase activity. Lung tissue myeloperoxidase (MPO) activity was assayed, as modified from the procedure of Goldblum et al. (18). At the end of the experiment, the lungs were washed with sterile saline and blotted dry. The tissue was homogenized on ice for $30 \mathrm{~s}$ in $0.5 \%$ hexadecyltrimethylammonium bromide (HTAB) in $50 \mathrm{mM}$ phosphate buffer $(\mathrm{pH}=6.0)$ and centrifuged at $40 \times 10^{3} \mathrm{~g}$ for $10 \mathrm{~min}$. The homogenate was decanted, and the pellet was resuspended in HTAB. Samples were freeze-thawed (for $20 \mathrm{~min}$ at $70^{\circ} \mathrm{C}$ ), followed by homogenization with polytron for $30 \mathrm{~s}$, and centrifugation at $40,000 \mathrm{~g}$ for 10 min at $4^{\circ} \mathrm{C}$. The supernatant MPO activity was assayed by mixing a $0.1-\mathrm{ml}$ aliquot of the sample with $2.9 \mathrm{ml}$ of $50 \mathrm{mM}$ PBS containing $0.167 \mathrm{mg} / \mathrm{ml} O$-dianibidine dihydrochloride (Sigma Chemical Co.) and $0.0005 \%$ hydrogen peroxide (Mallinckrodt, Paris, KY) to a final volume of $3 \mathrm{ml}$. Absorbance change was measured at $400 \mathrm{~nm}$ over a 3-min period, with the data derived by using a kinetic program. The unit of MPO is expressed as $\triangle \mathrm{Absorbance/min} \mathrm{per} \mathrm{g}$ tissue.

Statistics. Data are expressed as means \pm SEM. Differences from baseline values were determined by the one-way repeated measures analysis of variance followed by multiple comparisons utilizing $\mathrm{Tu}$ key's test (19). Statistical significance was accepted at $P<0.05$.

\section{Results}

ICAM-1 expression following $T N F_{\alpha}$ challenge. Increased binding of the anti-ICAM-1 mAb RR1/1 binding was detected on the pulmonary vascular endothelial cell membranes after 90 
min of $\mathrm{TNF}_{\alpha}$ stimulation (Fig. 2). RR1/1 immunoreactivity was not present in control lungs. The immunoreactivity detected by RR1/1 immunostaining was not the result of nonspecific RR1/1 binding, since the preabsorption control gave negative results (see Methods).

Effects of prestimulation with $T N F_{\alpha}$ on lung PMN uptake. Lung tissue MPO activity in control lungs $(n=5)$ perfused with Ringer's-albumin was minimal. MPO increased $(P<0.05)$ in lungs perfused with freshly isolated $\operatorname{PMN}(n=5)$ (Fig. 3). Challenge of PMN with PMA did not enhance the MPO activity. However, $\mathrm{TNF}_{\alpha}$ stimulation $(1,000 \mathrm{U} / \mathrm{ml}$ for $90 \mathrm{~min})$ increased MPO activity threefold over values of lungs perfused with PMN alone (from $3.62 \pm 1.06 \Delta / \mathrm{min}$ per $\mathrm{g}$ to $9.31 \pm 2.28 \Delta \mathrm{A}$ / min per g) (Fig. 3). In contrast, $\mathrm{TNF}_{\alpha}$ stimulation of lungs for 5

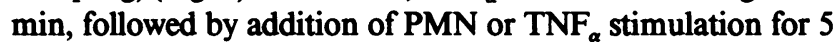
min, followed by addition of PMN 85 min later, did not increase the lung tissue MPO activity (MPO values of 3.06 \pm 1.2 and $3.42 \pm 1.2 \mathrm{~A} / \mathrm{min}$ per $\mathrm{g}$, respectively) (Table $\mathrm{I}$ ).

Treatment of PMN with mAb IB4 (anti-CD18) prevented the increase in MPO activity, whereas treatment with the control mAb OKM-1 (anti-CD1 lb) produced a similar increase in MPO, as in lungs challenged with $\mathrm{TNF}_{\alpha}$, for 90 min (Fig. 3). Treatment of lungs with $\mathrm{mAb}$ RR1/1 (which recognized ICAM-1 on endothelial cells) reduced the MPO activity by $58 \%$, an effect less $(P<0.05)$ than $98 \%$ reduction observed with IB4 treatment (Fig. 3).

Effect of $T N F_{\alpha}$ prestimulation on pulmonary edema formation. Challenge with PMA $\left(5 \times 10^{-9} \mathrm{M}\right)$ of the 90 -min $\mathrm{TNF}_{\alpha}-$ prestimulated lungs (in which PMN had been sequestered) pro- duced significant increases in pulmonary artery pressure $\left(\mathrm{P}_{\overline{\mathrm{pa}}}\right.$ (Fig. 4), pulmonary capillary hydrostatic pressure $\left(\mathrm{P}_{\overline{\mathrm{cap}}}\right)$ (Fig. 4), and lung wet weight (Fig. 5) over the 30-min study period following challenge with PMA. The final lung wet-to-dry weight ratio was increased in this group over others $(P<0.05)$ (Fig. 6). The increases in $P_{\overline{c a p}}$ and $P_{\overline{p a}}$ were threefold over baseline values (Fig. 4). The increase in lung wet weight of 120\% over the control lung wet weight values $(3.48 \pm 0.11 \mathrm{~g})$ (Fig. 5) was accompanied by edema fluid in the airways.

The increases in $P_{\overline{\mathrm{pc}}}, \mathbf{P}_{\mathrm{cap}}$, and lung wet weight after PMA challenge in the 90 -min $\mathrm{TNF}_{\alpha}$-prestimulated lungs perfused with PMN were significantly greater $(P<0.01)$ than in the other PMN-perfused groups (Figs. 4 and 5); that is, in (a) lungs perfused with PMN $\left(2 \times 10^{7}\right)$ alone; $(b)$ lungs perfused with PMN and then challenged with PMA; and (c) lungs prestimulated for $5 \mathrm{~min}$ with $\mathrm{TNF}_{\alpha}$, perfused with PMN, and challenged with PMA (group III, Table I). The effects of $\mathrm{TNF}_{\alpha}$ in the latter group were not delayed, in that 5-min $\mathrm{TNF}_{\alpha}$ treatment, followed by a wait of $85 \mathrm{~min}$, did not produce the effects observed with the 90 min of continuous $\mathrm{TNF}_{\alpha}$ treatment (group II, Table I).

The increases in $P_{\overline{p a}}, P_{c \bar{p}}$, and lung wet weight following PMA challenge in the 90-min $\mathrm{TNF}_{\alpha}$-stimulated lungs perfused with PMN were also greater $(P<0.05)$ than in the control groups (Figs. 4 and 5); i.e., (a) control (time-control lungs); (b) addition of PMA alone to Ringer's-albumin perfused lungs; $(c)$ 90-min $\mathrm{TNF}_{\alpha}$ challenge followed by addition of PMA to the perfusate; and $(d)$ 90-min $\mathrm{TNF}_{\alpha}$ challenge followed by addition of PMN to the perfusate.

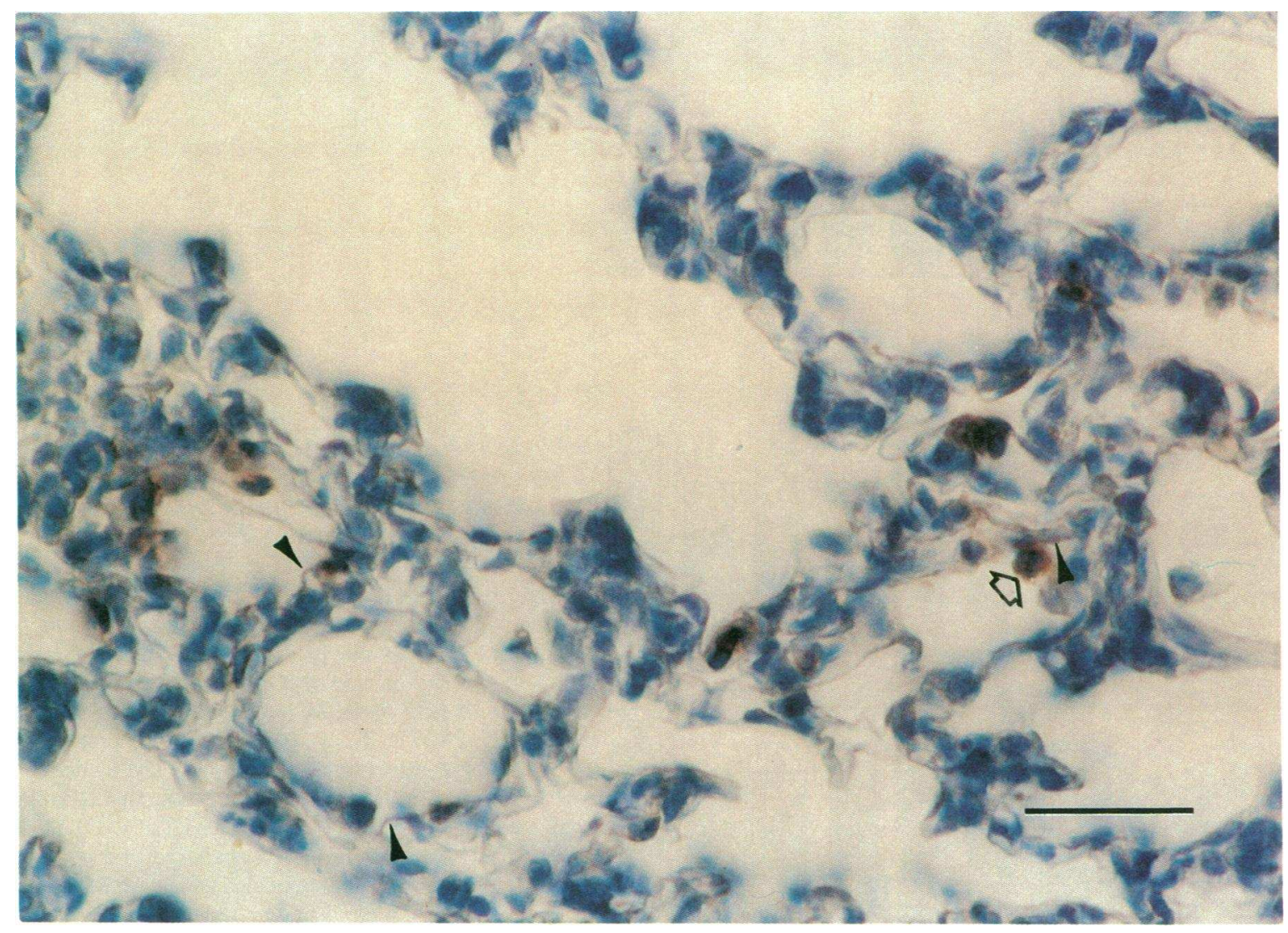

Figure 2. mAb RR1/1 immunostaining of pulmonary vascular endothelial cells (arrow) in guinea pig lung treated with $\mathrm{TNF}_{\alpha}$ for 90 min. Large arrow indicates an adherent PMN. The section was counterstained with hematoxylin. $\times 550$. Bar, $0.5 \mu \mathrm{m}$. 

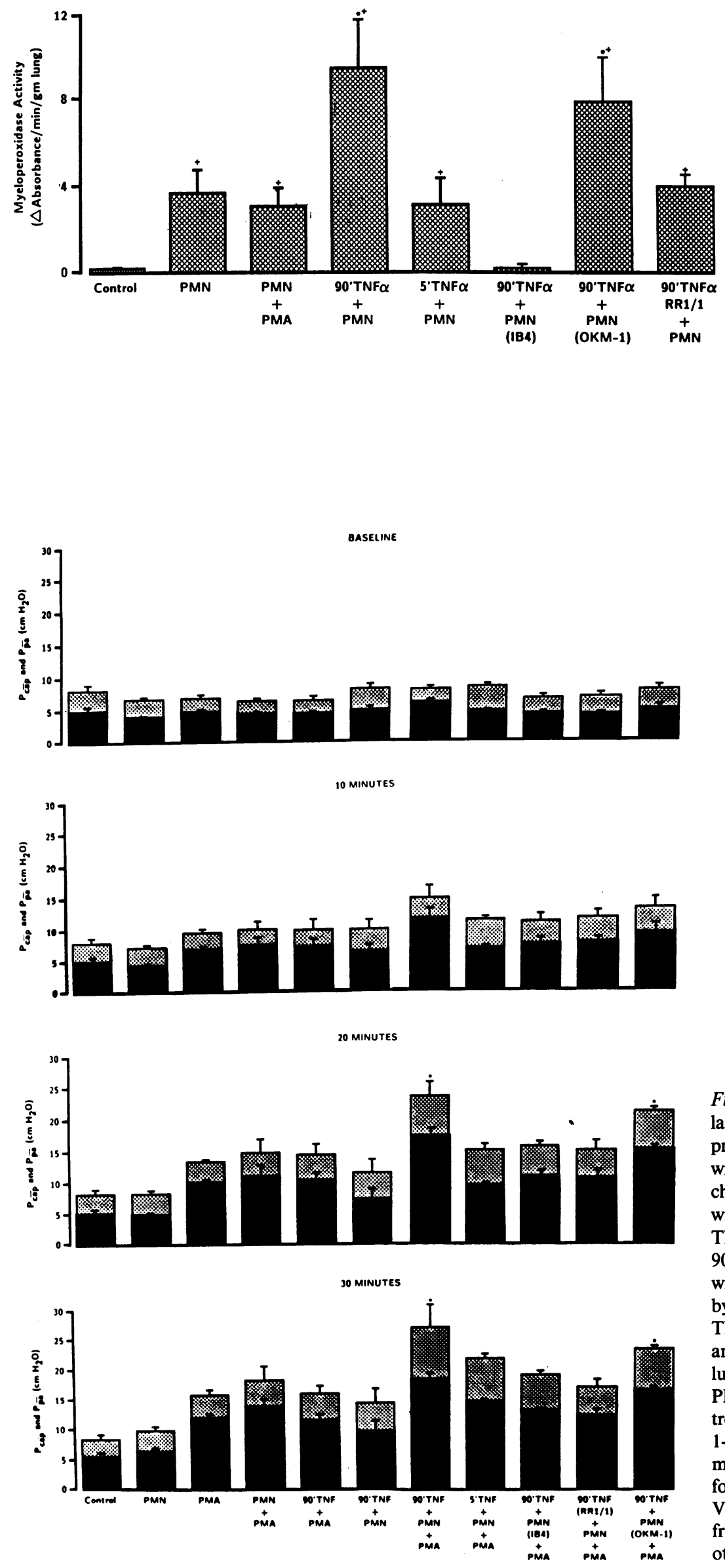

Figure 3. Lung tissue myeloperoxidase activities in the following groups: $(a)$ control lungs (i.e., guinea pig lungs perfused with Ringer's-albumin); (b) lungs perfused with $2 \times 10^{7}$ neutrophils (PMN); (c) lungs perfused with PMN followed by PMA challenge $\left(2 \times 10^{-9} \mathrm{M}\right) ;(d) 90$-min $\mathrm{TNF}_{\alpha}$-challenged lungs perfused with PMN; $(e)$ 5-min $\mathrm{TNF}_{\alpha}$-challenged lungs perfused with $\mathrm{PMN} ;(f)$ 90-min $\mathrm{TNF}_{\alpha}$-challenged lungs perfused with mAB IB4-treated PMN; $(g)$ 90-min $\mathrm{TNF}_{\alpha}$-challenged lungs perfused with $\mathrm{mAb} O \mathrm{OKM}$-1-treated PMN; and $(h)$ 90-min $\mathrm{TNF}_{\alpha}$-challenged lungs perfused with mAb RR1/1 perfused with PMN. Values are shown as mean \pm SEM. *Significant increase from other groups $(P<0.05)$; ${ }^{\dagger}$ Significant increase from control groups $(P<0.05)$.

Figure 4. Time course of changes in pulmonary capillary hydrostatic pressure $\left(\mathrm{P}_{\mathrm{cap}}\right)$ and pulmonary arterial pressure $\left(\mathrm{P}_{\overline{\mathrm{pa}}}\right)$ in $(a)$ control lungs; $(b)$ lungs perfused with neutrophils $(\mathrm{PMN})\left(2 \times 10^{7}\right.$ cells); $(c)$ control lungs challenged with PMA $\left(5 \times 10^{-9} \mathrm{M}\right) ;(d)$ lungs perfused with PMN followed by PMA challenge; (e) 90 -min TNF $_{\alpha}$-pretreated lungs followed by PMA challenge; $(f)$ 90-min $\mathrm{TNF}_{\alpha}$-pretreated lungs followed by perfusion with PMN; $(g)$ 90-min $\mathrm{TNF}_{\alpha}$-pretreated lungs, followed by PMN perfusion, and then PMA challenge; $(h) 5$-min $\mathrm{TNF}_{\alpha}$ pretreated lungs, followed by $\mathrm{PMN}$ perfusion, and then PMA challenge; $(i)$ 90-min $\mathrm{TNF}_{\alpha}$ pretreated lungs, followed by perfusion with mAb IB4-treated PMN, and then PMA challenge; $(j)$ 90-min $\mathrm{TNF}_{\alpha}$-pretreated lungs, followed by perfusion with $\mathrm{MAb} O K M-$ 1-treated PMN and then PMA challenge; and $(k)$ 90min $\mathrm{TNF}_{\alpha}$-pretreated lungs treated with $\mathrm{mAb} \mathrm{RR} 1 / 1$, followed by PMN perfusion, and then PMA challenge. Values are shown as means \pm SEM. *Significant change from 0 time point $(P<0.05)$. Significant changes from other groups $(P<0.05)$. 

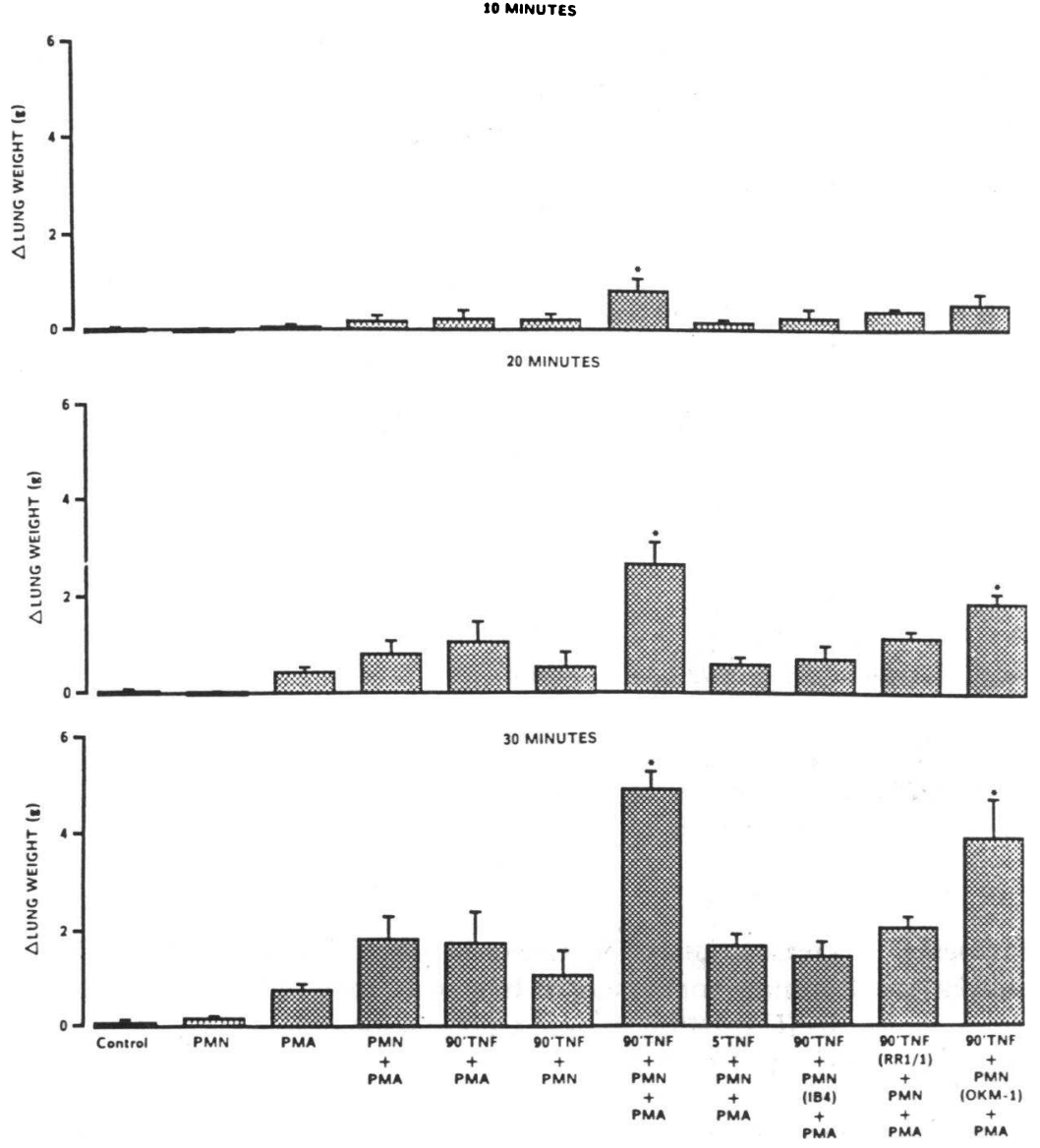

Figure 5. Time course of alterations in lung weight from baseline ( $\Delta$ lung weight) in ( $a$ ) control lungs; $(b)$ lungs perfused with neutrophils (PMN) $\left(2 \times 10^{7}\right.$ cells); (c) control lungs challenged with PMA $\left(5 \times 10^{-9} \mathrm{M}\right)$; (d) lungs perfused with PMA followed by PMA challenge; (e) 90-min $\mathrm{TNF}_{\alpha}$-pretreated lungs followed by PMA challenge; $(f)$ 90-min $\mathrm{TNF}_{\alpha}$-pretreated lungs followed by perfusion with PMN; $(g)$ 90-min $\mathrm{TNF}_{\alpha^{-}}$ pretreated lungs, followed by $P M N$ perfusion, and then PMA challenge; $(h)$ 5-min $\mathrm{TNF}_{\alpha}$ pretreated lungs, followed by PMN perfusion, and then PMA challenge; (i) 90-min $\mathrm{TNF}_{\alpha}$-pretreated lungs, followed by perfusion with $\mathrm{mAb}$ IB4-treated PMN, and then PMA challenge; $(j)$ 90-min $\mathrm{TNF}_{\alpha}$-pretreated lungs, followed by perfusion with mAb OKM-1-treated PMN, and then PMA challenge; and $(k)$ 90-min $\mathrm{TNF}_{\alpha}$-treated lungs treated with RR1/1, followed by PMN perfusion, and then PMA challenge. Values are shown as means \pm SEM. *Significant change from 0 time point $(P<0.05)$. Significant changes from other groups $(P<0.05)$.
Increased lung vascular permeability in $T N F_{\alpha}$-prestimulated lungs. Pulmonary edema formation after PMA challenge in the 90-min $\mathrm{TNF}_{\alpha}$-prestimulated lungs perfused with PMN was the result of increased lung vascular permeability, since raising $P_{\text {cap }}$ in control lungs (by increasing the pulmonary venous pressure) to the same level as in $\mathrm{TNF}_{\alpha}$-prestimulated lungs produced only a $20 \%$ increase in lung wet weight above control, whereas the lung wet weight increased $120 \%$ after PMN activation in the $\mathrm{TNF}_{\alpha}$-prestimulated lungs (Fig. 7). The increase in lung vascular permeability was also evident from the doubling of the capillary filtration coefficient $\left(K_{\mathrm{f}, \mathrm{c}}\right)$, observed after PMN challenge of PMN in the $\mathrm{TNF}_{\alpha}$-prestimulated lungs (Table II).

Effects of anti-CD18 and anti-ICAM-I mAbs on pulmonary edema formation. Pretreatment of PMN with $\mathrm{mAb}$ IB4 $(0.7 \mathrm{mg} / \mathrm{ml})$ prevented the increases in $\mathrm{P}_{\overline{\mathrm{pa}}}, \mathrm{P}_{\overline{\mathrm{cap}}}$, and pulmonary edema formation, whereas the control mAb OKM-1 $(0.7$ $\mathrm{mg} / \mathrm{ml}$ ) was ineffective (Figs. 4 and 5). Treatment of lungs with $\mathrm{mAb}$ RR1/1 $(0.7 \mathrm{mg} / \mathrm{ml}$; anti-ICAM-1) before addition of PMN to the perfusate also prevented the increases in $\mathrm{P}_{\overline{\mathrm{pa}}}, \mathrm{P}_{\overline{\mathrm{cap}}}$,

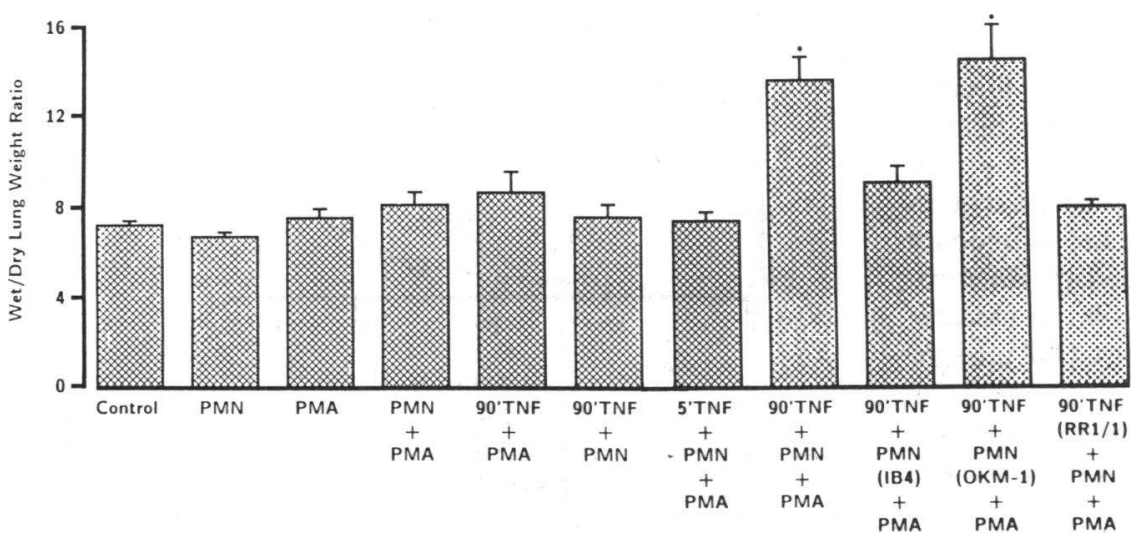

Figure 6. Wet-to-dry lung weight ratios in the (a) controls; (b) following neutrophil (PMN) perfusion of lungs; $(c)$ following PMA challenge of control lungs; $(d)$ following PMN perfusion followed by PMA challenge; $(e)$ 90min $\mathrm{TNF}_{\alpha}$ challenge following PMA challenge; (f) 90-min $\mathrm{TNF}_{\alpha}$ challenge followed by PMN perfusion of lungs; $(g) 5$-min $\mathrm{TNF}_{\alpha}$ challenge followed by PMN perfusion of lungs, and then challenged with PMA; $(h)$ 90-min $\mathrm{TNF}_{\alpha}$ challenge followed by PMN perfusion of lungs and then challenged with PMA; (i) 90-min TNF $\alpha$ challenge, followed by perfusion of lungs with mAb IB4-treated PMN, and then challenged with PMA; $(j)$ 90-min $\mathrm{TNF}_{\alpha}$ challenge of lungs followed by perfusion of lungs with $\mathrm{mAb}$

OKM-1-treated PMN and then challenged with PMA; and (k) 90-min challenge of lungs with TNF followed by addition of mAb RR1/1, perfusion of lungs with PMN, and then challenged with PMA. Values are shown as mean \pm SEM. *Significant change from other groups $(P<0.05)$. 
Table I. Pulmonary Hemodynamics, Lung Wet Weight, Wet-to-Dry Lung Weight Ratio, and Myeloperoxidase Activity after Activation of PMN with PMA in the Following Groups: (a) TNF $F_{\alpha}$ Challenge for 90 Min, Followed by Addition of PMN to the Perfusate (Group I); (b)

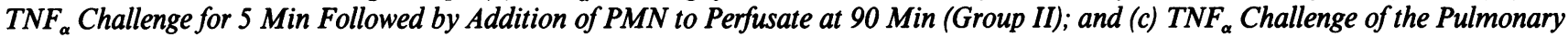
Vascular Bed for 5 Min, Followed by the Immediate Addition of PMN to Perfusate (Group III)

\begin{tabular}{|c|c|c|c|c|c|c|c|}
\hline & \multicolumn{2}{|c|}{$\underset{\mathrm{cm} \mathrm{H}_{2} \mathrm{O}}{\mathrm{P}_{\overline{\mathrm{A}}}}$} & \multicolumn{2}{|c|}{$\begin{array}{r}\mathbf{P}_{\overline{\mathrm{F}_{\mathrm{P}}}} \\
\mathrm{cm} \mathrm{H_{2 }} \mathrm{O}\end{array}$} & \multirow{2}{*}{$\begin{array}{c}\Delta W t \text { from } \\
\text { Baseline }(\mathrm{g}) \\
\quad 30\end{array}$} & \multirow{2}{*}{$\begin{array}{c}W / D \\
\left(g \cdot g^{-1}\right) \\
30\end{array}$} & \multirow{2}{*}{$\begin{array}{c}\text { MPO } \\
\left(\Delta \mathrm{A} \cdot \min ^{-1} \cdot \mathrm{g}^{-1}\right) \\
30\end{array}$} \\
\hline & 0 & 30 & 0 & 30 & & & \\
\hline & \multicolumn{7}{|c|}{$\min$} \\
\hline \multicolumn{8}{|l|}{ Group I } \\
\hline 90-min TNF/PMN + PMA & 8.0 & $26.8^{*}$ & 5.6 & $18.2^{*}$ & $+5.31^{*}$ & $13.32^{*}$ & $5.87^{*}$ \\
\hline$(n=6)$ & \pm 0.31 & \pm 2.4 & \pm 0.3 & \pm 0.7 & \pm 0.38 & \pm 0.69 & \pm 1.16 \\
\hline \multicolumn{8}{|l|}{ Group II } \\
\hline 5-min TNF/PMN (at $90 \mathrm{~min}$ ) & 6.8 & 16.8 & 4.4 & 12.4 & +1.41 & 7.33 & 3.42 \\
\hline+ PMA $(n=4)$ & \pm 0.7 & \pm 1.6 & \pm 0.5 & \pm 1.2 & \pm 0.40 & \pm 0.50 & \pm 1.18 \\
\hline \multicolumn{8}{|l|}{ Group III } \\
\hline 5-min TNF/PMN + PMA & 8.2 & 21.6 & 4.6 & 14.5 & +1.67 & 7.33 & 3.06 \\
\hline$(n=4)$ & \pm 0.4 & \pm 0.8 & \pm 0.2 & \pm 0.3 & \pm 0.25 & \pm 0.38 & \pm 1.20 \\
\hline
\end{tabular}

The values for the pressures are indicated for 0 time (baseline) and $30 \mathrm{~min}$ after challenge with PMA, and the other values are indicated at 30 min after the PMA challenge. Values are shown as mean $\pm S E M ;{ }^{*} P<0.05$ from other groups. $P_{\overline{\bar{p}}}$, mean pulmonary artery pressure; $P_{\overline{c a p}}$, pulmonary capillary pressure; W/D, wet/dry weight ratio; MPO, lung tissue myeloperoxidase activity.

and pulmonary edema to the same degree as mAb IB4 (Figs. 4 and 5). Both $\mathrm{mAbs}$ IB4 and RR1/1 also prevented the increases in $K_{\mathrm{f}, \mathrm{c}}$ (Table II).

Effect of cycloheximide. Cycloheximide $(10 \mu \mathrm{g} / \mathrm{ml})$ pretreatment of lungs inhibited the rises in $\mathrm{P}_{\overline{\mathrm{pa}}}, \mathrm{P}_{\overline{\mathrm{cap}}}$, lung weight change $(\Delta W)$, wet-to-dry lung weight ratio (W/D), and lung tissue MPO activity occurring with $90-\mathrm{min}^{\mathrm{TNF}} \mathrm{T}_{\alpha}$ stimulation, with the results identical to those with $\mathrm{mAb} R \mathrm{R} 1 / 1$ pretreatment (Table III). A lower concentration of cycloheximide (5 $\mu \mathrm{g} / \mathrm{ml}$ ) was only partially protective, compared with $10 \mu \mathrm{g} / \mathrm{ml}$. Cycloheximide alone did not produce significant alterations in pulmonary hemodynamic and weight parameters.

\section{Discussion}

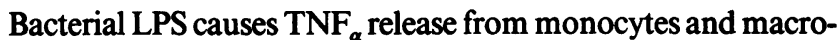
phages in septic patients $(1,3)$. Studies have indicated that plasma $\mathrm{TNF}_{\alpha}$ concentrations as high as $0.2 \mathrm{ng} / \mathrm{ml}$ can occur for periods up to $3 \mathrm{~h}$ in normal subjects challenged with endotoxin (1). In the present study, we used a $\mathrm{TNF}_{\alpha}$ concentration of 40 $\mathrm{ng} / \mathrm{ml}$ perfusate infused over $90 \mathrm{~min}$, which is in the range of what may be encountered in septicemia $(1,3)$. The findings indicate that $\mathrm{TNF}_{\alpha}$ prestimulation of lungs mediates neutrophil-dependent pulmonary edema, because activation of neutrophils (with phorbol 12-myristate 13-acetate [PMA]), sequestered as a result of the $\mathrm{TNF}_{\alpha}$, produced fulminant pulmonary edema. This permissive effect of $\mathrm{TNF}_{\alpha}$ was secondary to neutrophil uptake in the lungs, mediated by expression of vascular endothelial ICAM-1 "counter-receptor" for the CD18 integrin on neutrophils.

TNF $_{\alpha}$-induced upregulation of ICAM-1 is an important mechanism responsible for neutrophil uptake in the intact microcirculation. $\mathrm{TNF}_{\alpha}$ stimulation resulted in binding of the anti-ICAM-1 mAb (RR1/1) to the pulmonary vascular endothelial cell indicating ICAM-1 expression. Moreover, treatment of the lungs with mAb RR1/1 prevented $58 \%$ of the in- crease in lung tissue myeloperoxidase activity, indicating that a primary component of lung neutrophil uptake was mediated by ICAM-1 expression. Upregulation of ICAM- 1 by the treatment of pulmonary vasculature with $\mathrm{TNF}_{\alpha}$ for 90 min may involve de novo ICAM-1 protein synthesis, since a relatively short 60-120 min stimulation period with $\mathrm{TNF}_{\alpha}$ and IL-1 has been shown to induce ICAM-1 synthesis, and to mediate ICAM-1-dependent neutrophil adhesion to cultured vascular endothelial cells $(20,21)$. The finding that effects of cycloheximide were identical to those of $\mathrm{mAb} R R 1 / 1$ suggests that de novo ICAM-1 protein synthesis occurred secondary to $\mathrm{TNF}_{\alpha}$ stimulation. The lung uptake of neutrophils required a continuous 90 -min exposure period with $\mathrm{TNF}_{\alpha}$, as there was no response with the 5-min period of $\mathrm{TNF}_{\alpha}$ exposure.

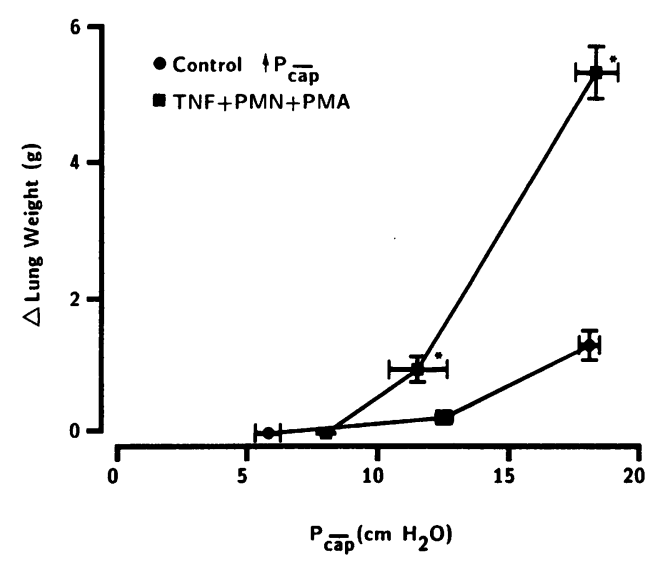

Figure 7. Change in lung wet weight ( $\Delta$ Lung Weight) following increase in pulmonary capillary hydrostatic pressure $\left(\mathbf{P}_{\mathrm{cap}}\right)$ by raising pulmonary venous pressure $(n=3)$, compared with the weight gain in $\mathrm{TNF}_{\alpha}$-challenged lungs after PMN activation with PMA (TNF + PMN + PMA group) over the same increments in $P_{\text {cap }}$. Bar, \pm SEM. *Significant difference. 
Table II. Pulmonary Capillary Filtration Coefficients $\left(K_{f, c}\right)$ in the Different Experimental Groups

\begin{tabular}{|c|c|c|c|c|c|c|}
\hline & Control & PMN & PMN + PMA & $\begin{array}{c}\text { TNF + PMN } \\
+ \text { PMA }\end{array}$ & $\begin{array}{c}\mathrm{TNF}+\mathrm{PMN} \\
(\mathrm{mAb} \text { IB4) } \\
+ \text { PMA }\end{array}$ & $\begin{array}{c}\text { TNF + PMN } \\
(\mathrm{mAb} \text { RR1/1) } \\
+ \text { PMA }\end{array}$ \\
\hline & $n=4$ & $n=3$ & $n=5$ & $n=3$ & $n=3$ & $n=3$ \\
\hline $\begin{array}{l}K_{\mathrm{f}, \mathrm{c}} \\
\quad\left(\mathrm{ml} / \mathrm{min} \text { per } \mathrm{cm} \mathrm{H}_{2} \mathrm{O} \text { per } \mathrm{g}\right) \\
\quad \times 10^{-2}\end{array}$ & $\begin{array}{r}5.87 \\
\pm 1.0\end{array}$ & $\begin{array}{r}5.76 \\
\pm 1.0\end{array}$ & $\begin{array}{r}6.88 \\
\pm 0.65\end{array}$ & $\begin{array}{l}11.32^{*} \\
\pm 0.90\end{array}$ & $\begin{array}{r}6.60 \\
\pm 0.60\end{array}$ & $\begin{array}{r}7.32 \\
\pm 0.31\end{array}$ \\
\hline
\end{tabular}

Values are shown in mean \pm SEM; ${ }^{*}$ Different from other groups $(P<0.05) ; n$, number of lungs; PMN, neutrophils; TNF, tumor necrosis factor alpha; PMA, phorbol 12-myristate-13-acetate; mAb, monoclonal antibody.

The uptake of neutrophils involved interaction of the leukocyte CD18 integrin with its ICAM-1 receptor. MAb IB4 directed against the common $\beta$-chain of CD11/CD18 glycoprotein complex inhibited neutrophil uptake (in this case the myeloperoxidase activity was reduced by $98 \%$ ), whereas the control mAb OKM-1 had no effect. Since inhibition with anti-ICAM-I $\mathrm{mAb}$ should be complete and equal to that of anti-CD18 mAb if ICAM-1 is the sole ligand for CD18, the results suggest that additional ligands for CD18 are present in the pulmonary microcirculation. Recent in vitro studies support the concept that CD18 can interact with other ligands such as ICAM-2 $(22,23)$ on cultured endothelial cells $(13,24,25)$.

We observed that neutrophil uptake in $90-\mathrm{min} \mathrm{TNF}_{\alpha}$ stimulated lungs was fully a CD18-dependent effect. Using intratracheal instillation of Streptococcus pneumoniae or hydrochloric acid in rabbits, Doerschuk et al. (26) showed CD18-independent neutrophil uptake in lungs. This difference may be attributed to the stimuli used in the two studies, and to possible differences in routes of administration. We have also observed that anti-CD18 mAb IB4 provided a similar inhibition of neutrophil uptake in guinea pig lungs challenged with intravenous Escherichia coli endotoxin $(27,28)$, indicating that endotoxin and $\mathrm{TNF}_{\alpha}$ after intravenous administration both mediate neutrophil uptake by CD18-dependent mechanism.

It is important to note that the uptake of neutrophils in the pulmonary vascular bed without the initial $\mathrm{TNF}_{\alpha}$-mediated priming did not increase vascular permeability or produce pulmonary edema. $\mathrm{TNF}_{\alpha}$-prestimulated lungs became edematous only after activation of the sequestered neutrophils. These data indicate that $\mathrm{TNF}_{\alpha}$-induced expression of ICAM-1, and possi- bly ELAM-1, is required for mediation of neutrophil uptake, and for the consequent development of lung vascular injury and edema. Pulmonary edema formation after neutrophil activation in the $\mathrm{TNF}_{\alpha}$-prechallenged lungs was the result of increases in both pulmonary capillary hydrostatic pressure (which increases the net transcapillary filtration pressure) and vascular endothelial permeability. The latter was evident by the increase in the pulmonary vessel wall filtration coefficient $\left(K_{\mathrm{f}, \mathrm{c}}\right)$, a measure of transvascular water permeability (14).

The basis of the pulmonary vasoconstriction and the resultant capillary hypertension after neutrophil activation in the $\mathrm{TNF}_{\alpha}$-prestimulated lungs is not clear. One possibility is that expression of endothelial adhesivity by $\mathrm{TNF}_{\alpha}$ enhances the activation response of the adherent neutrophils as has been shown in vitro experiments (12). Hence, there may be a greater release of pulmonary vasoconstrictor lipid mediators (e.g., thromboxane and peptidoleukotrienes) from the activated neutrophils. Neutrophils are the probable source of these mediators, since the augmented pulmonary vasoconstrictor response occurred only when neutrophils were activated with PMA in the $\mathrm{TNF}_{\alpha}$-primed lungs.

The anti-CD18 mAb IB4 prevented the pulmonary vasoconstriction, lung weight gain, and the increased lung vascular permeability. Addition of the anti-ICAM-1 mAb RR1/1 to the $\mathrm{TNF}_{\alpha}$-challenged lungs had the same protective effects as the anti-CD18 mAb, whereas RR1/1 partially inhibited the neutrophil uptake (58\% reduction), in contrast to the complete inhibition (98\% reduction) observed with the anti-CD18 mAb IB4. This finding is consistent with the in vitro observations that a critical neutrophil-to-endothelial cell ratio of $5: 1$ or $10: 1$ is re-

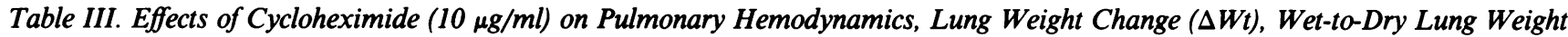
Ratio (W/D), and Lung Tissue Myeloperoxidase (MPO) Activity in Lungs Challenged with TNF for 90 Min Followed by Addition of PMN to the Perfusate, and Then by $P M A$

\begin{tabular}{|c|c|c|c|c|c|c|c|}
\hline & \multicolumn{2}{|c|}{$\underset{\left(\mathrm{cm} \mathrm{H_{2 }}\right.}{\left.\mathbf{P}_{\overline{\mathbf{P}}} \mathrm{O}\right)}$} & \multicolumn{2}{|c|}{$\underset{\left(\mathrm{cm} \mathrm{\textrm {H } _ { 2 }}\right.}{\mathrm{P}_{\overline{\bar{p}^{\prime}}}}$} & \multirow{2}{*}{$\frac{\Delta W t \text { from baseline }}{30 \mathrm{~min}}$} & \multirow{2}{*}{$\frac{W / D\left(g \cdot g^{-1}\right)}{30 \min }$} & \multirow{2}{*}{$\frac{\mathrm{MPO}\left(\Delta \mathrm{A} \cdot \mathrm{min}^{-1} \mathrm{~g}^{-1}\right)}{30 \mathrm{~min}}$} \\
\hline & 0 & $30 \mathrm{~min}$ & $\mathbf{0}$ & $30 \mathrm{~min}$ & & & \\
\hline Cycloheximide & 7.7 & 22.1 & 5.0 & 10.6 & +1.43 & 7.58 & 3.24 \\
\hline$(n=4)$ & \pm 0.8 & \pm 1.1 & \pm 0.6 & \pm 0.6 & \pm 0.6 & \pm 0.68 & \pm 2.34 \\
\hline mAb RR1/1 & 6.5 & 16.8 & 4.0 & 12.1 & +2.06 & 7.87 & 3.91 \\
\hline$(n=3)$ & \pm 0.6 & \pm 1.3 & \pm 0.3 & \pm 1.0 & \pm 0.23 & \pm 0.25 & \pm 0.52 \\
\hline
\end{tabular}

Results are compared with lungs receiving $\mathrm{mAb} R \mathrm{RR} 1 / 1$ and with same interventions. Values are shown as mean $\pm \mathrm{SEM}$. $\mathrm{P}_{\overline{\mathrm{pa}}}$, mean pulmonary artery pressure; $\mathrm{P}_{\overline{\text { cap }}}$, pulmonary capillary pressure. 
quired to mediate to endothelial injury (10), such that below this number endothelial injury does not occur. Therefore, the pulmonary hemodynamic and fluid balance alterations after neutrophil activation are likely dependent on the critical number of neutrophils sequestered in the pulmonary vascular bed.

In conclusion, the results indicate that $\mathrm{TNF}_{\alpha}$ prestimulation of the pulmonary vascular bed causes neutrophil uptake in lungs, a process dependent in part on expression of ICAM-1 antigen on pulmonary vascular endothelial cells, and the binding of ICAM-1 to the CD18 integrin on neutrophils. Other endothelial cell ligands interacting with CD18 may also be involved, since anti-CD18 mAb fully inhibited neutrophil uptake, whereas anti-ICAM-1 mAb produced a $58 \%$ reduction in the response. The activation of neutrophils sequestered in the $\mathrm{TNF}_{\alpha}$-primed lungs resulted in marked alterations in pulmonary hemodynamics and fluid balance, characterized by vasoconstriction, increased capillary hydrostatic pressure, increased vascular permeability, and fulminant pulmonary edema. We postulate that $\mathrm{TNF}_{\alpha}$ generation in septicemia is a critical factor mediating neutrophil-dependent acute lung injury through the expression of the endothelial adhesion molecule ICAM-1 and its interaction with the CD18 integrin on neutrophils.

\section{Acknowledgments}

We wish to thank Ms. Lynn McCarthy for her expert secretarial assistance, and Ms. Nancy Gertzberg for assistance with the graphics.

This work was supported by National Institutes of Health grants HL 32418 and HL 27016. S. K. Lo is a recipient of the Irvington Institute Postdoctoral Fellowship.

\section{References}

1. Michi, H. R., K. R. Manogue, D. R. Spriggo, A. Revhaug, S. O'Dwyer, C. A. Dinarello, A. Cerami, S. M. Wolff, and D. B. Wilmore. 1988. Detection of circulating tumor necrosis factor after endotoxin N. Eng. J. Med. 318:1481-1486.

2. Tracey, K. J., B. Beutler, S. F. Lowry, J. Merryweather, S. Wolpe, I. W. Milsark, R. J. Hariri, T. J. Fahey III, A. Zentella, J. D. Albert, G. T. Shires, and A. Cerami. 1986. Shock and tissue injury induced by recombinant human cachectin. Science (Wash. DC). 234:470-474.

3. Beutler, B., and A. Cerami. 1987. Cachectin: more than a tumor necrosis factor. N. Engl. J. of Med. 316:379-385.

4. Pohlman, T. H., K. A. Stanness, P. G. Beatty, H. D. Ochs, and J. M. Harlan. 1986. An endothelial cell surface(s) induced in vitro by lipopolysaccharide, interleukin-1, and tumor necrosis factor- $\alpha$ decreases neutrophil adherence by a CDw18-dependent mechanism. J. Immunol. 136:4548-4553.

5. Gamble, J. R., J. M. Harlan, S. J. Klebanoff, and M. A. Vadas. 1985. Stimulation of the adherence of neutrophils to umbilical vein endothelium by human recombinant tumor necrosis factor. Proc. Natl. Acad. Sci. USA. 82:86678671.

6. Bevilacqua, M. P., J. S. Pober, D. L. Mendrick, R. S. Cotran, and M. A. Gimbrone, Jr. 1987. Identification of an inducible endothelial-leukocyte adhesion molecule. Proc. Natl. Acad. Sci. USA. 84:9238-9242.

7. Dustin, M. L., and T. A. Springer. 1988. Lymphocyte function-associated antigen-1 (LFA-1) interaction with intercellular adhesion molecule-1 (ICAM-1) is one of at least three mechanisms for lymphocyte adhesion to cultured endothelial cells. J. Cell Biol. 107:321-331.

8. Dienner, A. M., P. G. Beatty, H. D. Ochs, and J. M. Harlan. 1985. The role of neutrophil membrane glycoprotein 150 (GP-150) in neutrophil-mediated endothelial cell injury in vitro. J. Immunol. 135:537-542.

9. Ismail, G., M. L. Moganroth, R. F. Todd III, and L. A. Boxer. 1987. Prevention of pulmonary injury in isolated perfused rat lungs by activated human neutrophils preincubated with anti-Mol monoclonal antibody. Blood. 69:11671172.

10. Gibbs, L. S., L. Lai, and A. B. Malik. 1990. Tumor necrosis factor enhances the neutrophil-dependent increases in endothelial monolayer permeability. J. Cell. Physiol. 145:496-500.

11. Kaslovsky, R. A., H. Lum, N. Gilboa, B. K. McCandless, S. D. Wright, and A. B. Malik. 1990. Pulmonary edema induced phagocytosing neutrophils: protective effect of monoclonal antibody against phagocyte CD18 integrin. Circ. Res. 46:795-802.

12. Nathan, C. F. 1987. Neutrophil activation on biological surfaces. Massive secretion of hydrogen peroxide in response to products of macrophages and lymphocytes. J. Clin. Invest. 80:1550-1560.

13. Lo, S. K., G. A. VanSeventer, S. M. Levin, and S. D. Wright. 1989. Two leukocyte receptors $\mathrm{CD} 1 \mathrm{1a} / \mathrm{CD} 18$ and $\mathrm{CD} 1 \mathrm{lb} / \mathrm{CD} 18$ mediate transient adhesion to endothelium by binding to different ligands. J. Immunol. 143:3325-3329.

14. Selig, W. M., T. C. Noonan, D. F. Kern and A. B. Malik. 1986. Pulmonary microvascular responses to arachidonic acid in isolated perfused guinea pig lung. J. Appl. Physiol. 60:1972-1979.

15. Ferrante, A., and Y. H. Thong. 1986. Optimal conditions for simultaneous purification of mononuclear and polymorphonuclear leukocytes for human blood by the Hypaque-Ficoll method. J. Immunol. Methods. 36:109-117.

16. Huang, W. M., S. J. Gibson, P. Facer, J. Gu, and J. M. Pollak. 1983. Improved section adhesion for immunocytochemistry using high molecular weight polymers of L-lysine as a slide coating. Histochemistry. 77:275-282.

17. Hsu, S. M., L. Raine, and H. Ganges. 1981. Use of avidin-biotin-peroxidase complex $(\mathrm{ABC})$ in immunoperoxidase techniques: a comparison between $\mathrm{ABC}$ and unlabeled antibody (PAP) procedure. J. Histochem. Cytochem. 29:577582 .

18. Goldblum, S. E., K. M. Wu, and M. Jay. 1985. Lung myeloperoxidase as a measure of pulmonary leukostasis in rabbits. J. Appl. Physiol. 59:1978-1985.

19. Steel, R. G. D., and J. H. Torrie. 1980. Principles and Procedures of Statistics. McGraw-Hill Inc., New York. pp. 1-186.

20. Springer, T. A. 1990. Adhesion receptors of the immune system. Nature (Lond.). 346:425-433.

21. Pober, J. S., and R. S. Cotran. 1990. Cytokines and endothelial cell biology. Physiol. Rev. 70:427-452.

22. Diamond, M. S., D. E. Staunton, S. D. Marlin, and T. A. Springer. 1991. Binding of the integrin Mac-1 (CD1 1b/CD18) to the third immunoglobulin-like domain of ICAM-1 (CD54) and its regulation by glycosylation. Cell. 65:961-971.

23. de Fougerolles, A. R., S. A. Stalker, R. Schwarting, and T. A. Springer. 1991. Characterization of ICAM-2 and evidence for a third counter-receptor for LFA-1. J. Exp. Med. 174:253-267.

24. Smith, C. W., R. Rothlein, B. J. Hughes, M. M. Mariscalco, H. E. Rudloff, F. C. Schmalsteig, and D. C. Anderson. 1988. Recognition of an endothelial determinant for CD18-dependent human neutrophil adherence and transendothelial migration. J. Clin. Invest. 82:1746-1756.

25. Staunton, D. E., M. L. Dustin, and T. A. Springer. 1989. Functional cloning of ICAM-2, a cell adhesion ligand for LFA-1 homologous to ICAM-1. Nature (Lond.). 339:61-64.

26. Doerschuk, C. M., M. F. Allard, H. O. Coxson, R. K. Winn, and J. M. Harlan. 1990. CD18-dependent and independent mechanisms of neutrophil emigration in the pulmonary and systemic microvasculature of rabbits. J. Immunol. 144:2327-2333.

27. Horgan, M. J., J. Everitt, G. P. Palace, and A. B. Malik. 1991. Endotoxininduced release of tumor necrosis factor in lungs. FASEB (Fed. Am. Soc. Exp. Biol.) J. 5:A847.

28. Cooper, J. A., P. H. Neuman, S. D. Wright, and A. B. Malik. 1989. Pulmonary vascular sequestration of neutrophils in endotoxemia: role of $\mathrm{CD} 18$ leukocyte surface glycoprotein. Am. Rev. Respir. Dis. 139:A301. 